\title{
Survival of Mexican Children with Acute Lymphoblastic Leukaemia under Treatment with the Protocol from the Dana-Farber Cancer Institute 00-01
}

\author{
Elva Jiménez-Hernández, ${ }^{1}$ Ethel Zulie Jaimes-Reyes, ${ }^{1}$ José Arellano-Galindo, ${ }^{2}$ \\ Xochiketzalli García-Jiménez, ${ }^{3}$ Héctor Manuel Tiznado-García, ${ }^{1}$ \\ María Teresa Dueñas-González, ${ }^{1}$ Octavio Martínez Villegas, ${ }^{1}$ Berenice Sánchez-Jara, ${ }^{1}$ \\ Vilma Carolina Bekker-Méndez, ${ }^{1}$ María Guadalupe Ortíz-Torres, ${ }^{1}$ \\ Antonio Ortíz-Fernández, ${ }^{1}$ Teresa Marín-Palomares, ${ }^{1}$ and Juan Manuel Mejía-Aranguré ${ }^{4}$ \\ ${ }^{1}$ Departamento de Hematología Pediátrica, Unidad Médica de Alta Especialidad (UMAE), Centro Médico Nacional "La Raza", \\ Instituto Mexicano del Seguro Social (IMSS), Avenida Jacarandas Esquina Vallejo S/N colonia La Raza, 02990 Mexico, DF, Mexico \\ ${ }^{2}$ Laboratorio de Investigación, Hospital Infantil de México "Federico Gómez", Secretaría de Salud, Calle Doctor Marquez 162, \\ Colonia Doctores, Delegación Cuauhtémoc, 06720 Mexico, DF, Mexico \\ ${ }^{3}$ Facultad de Medicina, Universidad Nacional Autónoma de México, Avenida Universidad 3000, 04510 Mexico City, DF, Mexico \\ ${ }^{4}$ Unidad de Investigación en Epidemiología Clínica, UMAE Hospital de Pediatría, Centro Médico Nacional "Siglo XXI", IMSS, \\ Avenida Cuauhtemoc 330, 4to Piso Edificio de la Academia Nacional de Medicina, 06720 Mexico, DF, Mexico
}

Correspondence should be addressed to Juan Manuel Mejía-Aranguré; juan.mejiaa@imss.gob.mx

Received 4 July 2014; Revised 3 October 2014; Accepted 17 October 2014

Academic Editor: Richard J. Q. McNally

Copyright (C) 2015 Elva Jiménez-Hernández et al. This is an open access article distributed under the Creative Commons Attribution License, which permits unrestricted use, distribution, and reproduction in any medium, provided the original work is properly cited.

Our aim in this paper is to describe the results of treatment of acute lymphoblastic leukaemia (ALL) in Mexican children treated from 2006 to 2010 under the protocol from the Dana-Farber Cancer Institute (DFCI) 00-01. The children were younger than 16 years of age and had a diagnosis of ALL de novo. The patients were classified as standard risk if they were 1-9.9 years old and had a leucocyte count $<50 \times 10^{9} / \mathrm{L}$, precursor B cell immunophenotype, no mediastinal mass, CSF free of blasts, and a good response to prednisone. The rest of the patients were defined as high risk. Of a total of 302 children, $51.7 \%$ were at high risk. The global survival rate was $63.9 \%$, and the event-free survival rate was $52.3 \%$ after an average follow-up of 3.9 years. The percentages of patients who died were $7 \%$ on induction and $14.2 \%$ in complete remission; death was associated mainly with infection (21.5\%). The relapse rate was $26.2 \%$. The main factor associated with the occurrence of an event was a leucocyte count $>100 \times 10^{9} / \mathrm{L}$. The poor outcomes were associated with toxic death during induction, complete remission, and relapse. These factors remain the main obstacles to the success of this treatment in our population.

\section{Introduction}

Acute lymphoblastic leukaemia (ALL) is the most common cancer in children and adolescents and is the most frequent cancer in Hispanic children including Mexican children [1]. In developed regions, including North America, Eastern Europe, Australia, New Zealand, and Japan, the survival after 5 years is $>90 \%$ and the cure rate is $85 \%$ [2-6]. These results are now possible because of the implementation of clinical assays involving cooperation between countries [711]. However, in developing countries, the survival rate is low, possibly because of the lower quality of medical attention [12]. Several factors are included in the classification of risk: clinical, cytogenetic, immunological, and molecular [13-17]. Despite the availability of these factors for classifying risk, in several developing countries the 1993 National Cancer Institute (NCI) criteria [18] continues to be used for the classification of relapse risk. These criteria take into account 


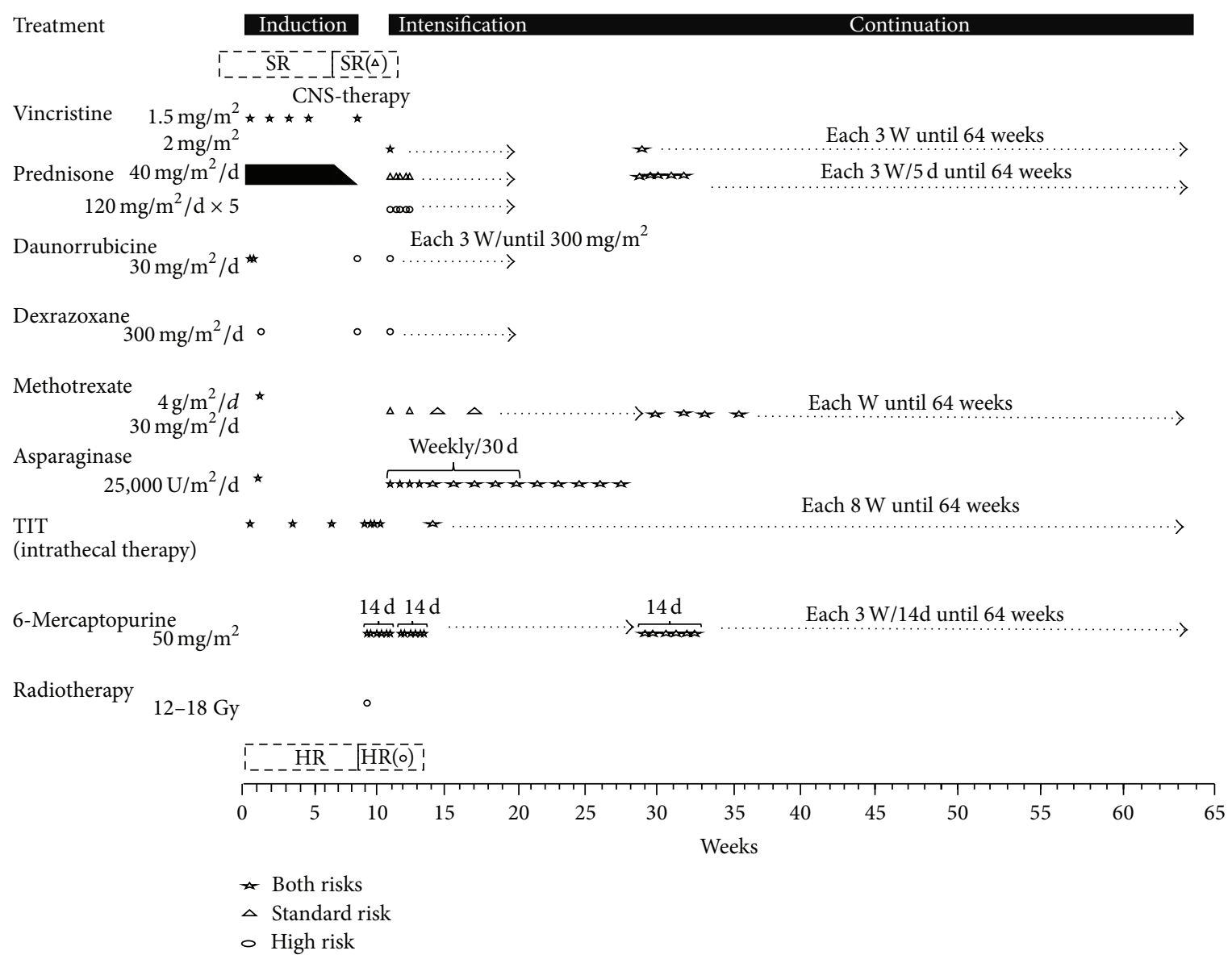

FIGURE 1: DCFI 00-01 therapy in paediatric patients with ALL who were younger than 16 years of age and who were treated at the paediatric haematology service of the specialist "La Raza" IMSS Medical Centre.

the age, leucocyte count, immunophenotype, and the recent response to prednisone, the latter of which has been proven as a strong predictor of response in several groups [19-21].

The Dana-Farber Cancer Institute (DFCI) ALL Consortium is a collaborative group that developed clinical assays from 1985 to 2000 . The basis of the treatment is 20-30 dosages of asparaginase during intensification and frequent pulses of vincristine and steroid during maintenance. The survival rates obtained from treatments using this protocol were $82 \%$ in the 1980 s and $88 \%$ in the 1990 s $[22,23]$.

In this paper, we report on our results obtained in a group of Mexican children with acute lymphoblastic leukaemia treated with the DFCI 00-01 protocol modified for our local conditions.

\section{Patients and Methods}

2.1. Patients. From August 2006 to December 2010, paediatric patients with ALL who were younger than 16 years of age and who were treated at the paediatric haematology service at the Centro Médico Nacional "La Raza” IMSS were selected. Patients with a diagnosis of mature cells ALL-B mature were not included. The protocol was approved by the institutional committees, and informed consent was obtained from the parents of each patient.

2.2. Risk Groups. The patients were stratified according to their risk as standard risk (SR) or high risk (HR). SR was defined as patients 1-9.9 years old, leucocyte count $<50 \times$ $10^{9} / \mathrm{L}$, precursor $\mathrm{B}$ cell phenotype, absence of a mediastinal mass, spinal fluid without blastic cells, and good response to the prednisone window. HR was defined as all patients not in the SR group.

2.3. Therapy. The treatment scheme is shown in Figure 1. Our patients have received the treatment mentioned previously since 1998. At that time, the classification was based on age and leucocyte count. In our hospital, the immunophenotype, cytogenetic study results, and molecular biology data were not available. In this report, we include those patients who were treated under the DFCI 00-01 protocol adapted to the local conditions without a window of investigation. All patients had been treated with a prednisone window comprising $60 \mathrm{mg} / \mathrm{m}^{2} \mathrm{SC}$ for 7 days and intrathecal chemotherapy with methotrexate on day 0 , and the induction to remission was 4 weeks. The anthracycline drug was daunorubicin 
instead of doxorubicin. CNS therapy was applied once complete haematological remission was reached. Afterwards, all patients received triple CNS intrathecal chemotherapy two times per week in four dosages adjusted according to the patient's age. The HR patients with major risk of relapse also received radiotherapy $(12 \mathrm{~Gy})$ to the brain.

All patients continued the intensification phase for 30 weeks. For the SR group, vincristine $2 \mathrm{mg} / \mathrm{m}^{2}$ at day 1 and each 3 weeks, asparaginase from Escherichia coli 25,000 UI/m², and methotrexate $40 \mathrm{mg} / \mathrm{m}^{2}$ by intramuscular injection each week and 1 day after asparaginase were administrated. Prednisone was administered orally at $40 \mathrm{mg} / \mathrm{m}^{2}$ for 5 days and 6 -mercaptopurine $50 \mathrm{mg} / \mathrm{m}^{2} /$ day for 14 days. The HR group received additional intravenous daunorubicin $30 \mathrm{mg} / \mathrm{m}^{2}$ at day 1 and each three weeks. The stopping dose of daunorubicin was $300 \mathrm{mg} / \mathrm{m}^{2}$, dexrazoxane $300 \mathrm{mg} / \mathrm{m}^{2}$ before daunorubicin, and prednisone $120 \mathrm{mg} / \mathrm{m}^{2} /$ day for 5 days. In patients who exhibited an allergic reaction to $E$. coli asparaginase, the treatment was suspended with no other option because another form of asparaginase was not available in our service. The maintenance was for 64 weeks. Either the SR or HR group the patients had received vincristine, prednisone, 6-mercaptopurine, and methotrexate equally than the intensification, but the $H R$ group had received prednisone to $40 \mathrm{mg} / \mathrm{m}^{2}$ and intrathecal chemotherapy with triple drug every 8 weeks until the treatment was completed.

2.4. Response and Relapse Criteria. The prednisone response was determined using the absolute count of blasts in the peripheral blood on day 8 after 7 days of prednisone and one dose of intrathecal methotrexate on day 1 . A poor response to prednisone (PRP) was defined as a blast count of $\geq 1 \times$ $10^{9} / \mathrm{L}$, and a good response to prednisone (GRP) was defined as a blast count of $<1 \times 10^{9}$ blasts. The response of the bone marrow to the induction therapy was evaluated on days 14 and 28. Complete remission was defined as $<5 \%$ of blasts in bone marrow and without extramedullary disease.

Relapse was defined as an emergence of the disease with $\geq 25 \%$ of blasts in either bone marrow or extramedullary or both. Early death was defined as the death of a patient before evaluation of the remission stage on day 28 or 35 after the induction of remission. Event-free survival was defined as the time to the occurrence of resistance, relapse, death, or a second neoplasm. Global survival was defined as the time in months from the diagnosis to death from any cause or the last contact with the patient in the outpatient clinic or hospital.

2.5. Statistical Analysis. Qualitative variables are presented as absolute numbers or percentages. Quantitative variables are presented as median value, as a measure of central tendency, and as a range between the minimum and maximum values. For quantitative variables without a normal distribution, the medians were compared using the Mann-Whitney $U$ test for two independent groups. For qualitative variables, the chisquare or Fisher's exact test were used. $P<0.05$ was considered to indicate that the difference had a low probability of a random error. The prednisone response was evaluated
TABLE 1: Demographic and baseline characteristics of the study population $(N=302)$.

\begin{tabular}{|c|c|c|c|}
\hline Characteristic & $n$ & $\%$ & $\operatorname{Median}(\mathrm{m} / \mathrm{m})$ \\
\hline Total & 302 & 100 & \\
\hline Male & 167 & 53.3 & \\
\hline Female & 135 & 44.7 & \\
\hline Age (years) & & & $7(<1-15)$ \\
\hline \multicolumn{4}{|l|}{ Age groups (years) } \\
\hline$<1$ & 1 & 0.3 & \\
\hline $1-5$ & 122 & 40.4 & \\
\hline $5.1-9.99$ & 66 & 21.9 & \\
\hline$\geq 10$ & 113 & 37.4 & \\
\hline \multicolumn{4}{|l|}{ Immunophenotype } \\
\hline $\mathrm{B}$ & 279 & 92.4 & \\
\hline $\mathrm{T}$ & 23 & 7.6 & \\
\hline Leucocyte count $(1 \times$ & & & $10,790(720-939,830)$ \\
\hline \multicolumn{4}{|c|}{ Groups of leucocyte count } \\
\hline$<10$ & 147 & 48.7 & \\
\hline $10-20$ & 48 & 15.9 & \\
\hline $20-50$ & 34 & 11.3 & \\
\hline $50-100$ & 27 & 8.9 & \\
\hline$>100$ & 46 & 15.2 & \\
\hline NCS infiltration & 8 & 2.6 & \\
\hline Testicular infiltration & 4 & 1.3 & \\
\hline \multicolumn{4}{|l|}{ Prednisone response } \\
\hline Good & 242 & 80.1 & \\
\hline Poor & 60 & 19.9 & \\
\hline SR & 146 & 48.3 & \\
\hline HR & 156 & 51.7 & \\
\hline
\end{tabular}

$(\mathrm{m} / \mathrm{m}):$ minimum/maximum.

using a Kaplan-Meier survival analysis and the groups were compared using the log-rank test. Confounding variables in the analysis of the prednisone response were analysed using the Cox proportional-hazard model. All analyses were performed using SPSS statistical package version 21. Two analyses of survival were performed after 3 years and 5 years of follow-up. All of the children had complete data for the 3year follow-up, but only 158 (52.3\%) had data for the 5-year follow-up.

\section{Results}

A total of 302 children met the inclusion criteria and were included during the study period. There were more boys (53.3\% boys). The median age was 7 years, and most of these patients were 1-5-year-old (40.4\%). Most patients $(92.4 \%)$ were classified with the precursor B phenotype.

The most frequent leucocyte count in these patients was $<10 \times 10^{9} / \mathrm{L}$; the median was $10,790 \times 10^{9} / \mathrm{L}$. Interestingly, at the time of diagnosis, only $2.6 \%$ had CNS infiltration even though most patients (51.7\%) were classified as HR.

Most of the patients had an initial good response to prednisone $(80.1 \%)$ (Table 1 ), and $90.4 \%$ of these patients had 
TABLE 2: Treatment responses $(N=302)$.

\begin{tabular}{lccc}
\hline & $n$ & $\%$ & median $(\mathrm{m} / \mathrm{m})$ \\
\hline Complete remission & 273 & 90.4 \\
Failure & 8 & 2.6 \\
Early death & 21 & 7.0 \\
Treatment dropout & 6 & 2.0 \\
Relapse & & & \\
$\quad$ No & 223 & 73.8 \\
$\quad$ Yes & 79 & 26.2 \\
Time of relapse & & \\
$\quad$ Very early & 27 & 8.9 \\
$\quad$ Early & 40 & 13.2 \\
$\quad$ Late & 12 & 4.0 \\
Site of relapse & & \\
$\quad$ Bone marrow (BM) & 55 & 18.2 \\
$\quad$ NCS & 8 & 2.6 \\
$\quad$ BM + NCS & 13 & 4.3 \\
$\quad$ Testicle & 3 & 1.0 \\
Dead & 193 & 63.9 \\
$\quad$ Alive & 109 & 36.1 \\
Duration of follow-up (years) & & & $3.9(7$ days-7.3) \\
\hline
\end{tabular}

$\mathrm{m} / \mathrm{m}$ : minimum/maximum.

a complete remission. The median follow-up was 3.9 years. The frequency of early mortality was $7 \%$, and the frequency of relapse was $26.2 \%$. Most cases of relapse were early relapse, mainly in the bone marrow (18.2\%). The global mortality was $36.1 \%$ (Table 2). Because all patients had completed the 3 years of follow-up, the presence of events for relapse and death was estimated for 3 and 5 years.

3.1. Three-Year Follow-Up (Tables 3, 4, and 5). Relapse was more frequent in the boys $(24.6 \%)$. However, the girls had a higher frequency of events at $42.2 \%$.

The highest relapse frequency was observed in the group aged 5.1-9.9 years (25.8\%), who experienced a high frequency of events (47\%). The age group with the highest mortality was the group aged $>10$ years (36.3\%; RR 1.70, 95\% CI 1.0-2.8).

The patients with the $\mathrm{T}$ cell immunophenotype had the highest frequency of death (47.8\%; RR 2.1, 95\% CI 1.1-4.1).

The SR patients had higher frequencies of relapse (25.3\%) and events (42.5\%). Most relapses (28.3\%) occurred in patients with a leucocyte count $>100 \times 10^{9} / \mathrm{L}$. This group of patients also had the highest frequency of events $(50 \%$; RR $1.84,95 \%$ CI 1.0-3.3). However, $37.5 \%$ of the patients who died had a range of leucocyte count of $10-20 \times 10^{9} / \mathrm{L}$.

3.2. Five-Year Follow-Up. Boys had a higher frequency of relapse (30.5\%), but there was no difference between boys and girls for the frequency of events. The frequency of death was $38.5 \%$ in the girls (RR 1.41; 95\% CI 1.0-2.1).

The highest frequency of relapse was in the group age $>10$ years $(75.2 \%)$ and this group had the highest frequency of events (58.7\%).
The highest frequency of relapse was observed in patients with leukaemia of B cell lineage (26.9\%). The mortality rate was highest in patients with T cell leukaemia (52.2\%; RR 1.93, 95\% CI 1.0-3.7).

The SR group had a higher frequency of relapse (30.1\%) and higher frequency of events (47.9\%). The highest frequency of relapse was observed in the group with a leucocyte count $>100 \times 10^{9} / \mathrm{L}(30.4 \%)$. This group also had the highest frequency of events (58.7\%; RR 2.02, 95\% CI 1.2-3.5) and highest mortality (45.7\%; RR 1.86, 95\% CI 1.0-3.7).

The factor that was most strongly associated with the occurrence of events at the 5-year follow-up was a leucocyte count $>100 \times 10^{9} / \mathrm{L}$. Leucocyte count and the $\mathrm{T}$ cell immunophenotype were also associated with a higher risk of mortality at 5 years.

Of the 302 patients, 21 (7\%) died during induction to remission (IR) and 43 (14.2\%) died during complete remission. The causes of death were sepsis $(65,21.5 \%)$, haemorrhage $(9,8.7 \%)$, pneumonia $(7,6.7 \%)$, and typhlitis (4, $3.8 \%)$. The global mortality was of $36.1 \%$, and $13(12.5 \%)$ died in leukaemic activity. Toxicity associated with asparaginase was observed in $29 \%$ of all patients. The most common toxicity was an allergic reaction in 19\%, pancreatitis in $7 \%$, thrombosis in 3\%, and only one involving the CNS. All of these reactions led to a definitive suspension of the drug.

\section{Discussion}

In our patient population, which was treated using the DFCI 00-01 protocol, after a median follow-up of 3.9 years, the global survival and event-free survival rates were lower than those obtained from the DFCI Consortium reports in a 5year follow-up (63.9\% and $52.3 \%$ versus $90 \%$ and $81 \%$, resp., for the group treated with prednisone). There were other differences between our patients and those reported by other groups. For example, in our study, most patients were in the HR group [7-11], which may have influenced our results. The high mortality rate during induction (7\%) may be associated with the delayed arrival of the patient at our hospital, bad conditions, tumour load, malnutrition, presence of infection, or toxicity of the treatment [24]. Our results are similar to those reported previously by another centre in Mexico [25] and by a multicentre study in Central America (AHOPCA and Pacheco et al.) [26, 27], which reported mortality rates of $3 \%$ and $7 \%$ during IR. In our study, $80.1 \%$ showed a prednisone good response (PGR), whereas $>90 \%$ of patients showed a PGR in two other studies $(8,29)$. To our knowledge, no studies have reported on a diminished response to steroid in the Hispanic population.

Other factors were hyperleukocytosis (15.2\%), which has been reported previously. When the leucocyte count is $>200$ $\times 10^{9} / \mathrm{L}[28,29]$, the toxicity of the treatment is associated with a high percentage of deaths during complete remission $(14.2 \%)$ and with the presence of an infectious disease leading to septic shock (21.5\%).

A higher frequency of relapse (26.2\%) was observed in our patients compared with other studies $[22,23,29]$. The factors associated with relapse at the 3 - and 5-year follow-ups 
TABLE 3: Relapses and deaths in paediatric patients with ALL who were younger than 16 years of age and who were treated at the paediatric haematology service of the specialist "La Raza" IMSS Medical Centre.

\begin{tabular}{|c|c|c|c|c|c|c|c|c|c|}
\hline$N=302$ & $\begin{array}{l}\text { Total } \\
n(\%)\end{array}$ & $\begin{array}{c}\text { Relapse } \\
\text { (at } 3 \text { years) } \\
n(\%)\end{array}$ & $\begin{array}{c}\text { Not Relapse } \\
\text { (at } 3 \text { years) } \\
n(\%)\end{array}$ & $\begin{array}{c}\text { Relapse } \\
\text { (at } 5 \text { year) } \\
n(\%)\end{array}$ & $\begin{array}{c}\text { No Relapse } \\
\text { (at } 5 \text { years) } \\
n(\%)\end{array}$ & $\begin{array}{c}\text { Death } \\
\text { (at } 3 \text { years) } \\
n(\%)\end{array}$ & $\begin{array}{c}\text { Lives } \\
\text { (at } 3 \text { years) } \\
n(\%)\end{array}$ & $\begin{array}{c}\text { Death } \\
\text { (at } 5 \text { years) } \\
n(\%)\end{array}$ & $\begin{array}{c}\text { Lives } \\
\text { (at } 5 \text { years) } \\
n(\%)\end{array}$ \\
\hline \multicolumn{10}{|l|}{ Sex } \\
\hline Male (\%) & $167(100)$ & $41(24.6)$ & $126(75.4)$ & $51(30.5)$ & $116(69.5)$ & $48(28.7)$ & $119(71.3)$ & $54(32.3)$ & $113(67.7)$ \\
\hline Female (\%) & $135(100)$ & $26(19.3)$ & $109(80.7)$ & $28(20.7)$ & $107(79.3)$ & $44(32.6)$ & $91(67.4)$ & $52(38.5)$ & $83(61.5)$ \\
\hline \multicolumn{10}{|l|}{ Age (years) } \\
\hline$<1$ & $1(100)$ & $1(100)$ & $0(0.0)$ & $1(100)$ & $0(0.0)$ & $0(0)$ & $1(100)$ & $1(100)$ & $0(0.0)$ \\
\hline $1-5$ & $122(100)$ & $25(20.5)$ & $97(79.5)$ & $31(25.4)$ & $91(74.0)$ & $29(23.8)$ & $93(76.2)$ & $35(28.7)$ & $87(71.3)$ \\
\hline $5.1-9.99$ & $66(100)$ & 17 (25.8) & $49(74.2)$ & $19(28.8)$ & 47 (71.2) & $22(33.3)$ & $44(66.7)$ & $26(39.4)$ & $40(60.6)$ \\
\hline$\geq 10$ & $113(100)$ & $24(21.2)$ & 89 (78.7) & $28(24.8)$ & $85(75.2)$ & $41(36.3)$ & $72(63.7)$ & $44(38.9)$ & $69(61.1)$ \\
\hline \multicolumn{10}{|l|}{ Lineage } \\
\hline B & $279(100)$ & $73(22.6)$ & $216(77.4)$ & $75(26.9)$ & $204(73.1)$ & $81(29.0)$ & $198(71.0)$ & $94(33.7)$ & $185(66.3)$ \\
\hline $\mathrm{T}$ & $23(100)$ & $4(17.4)$ & 19 (82.6) & $4(17.9)$ & $19(82.6)$ & $11(47.8)$ & $12(52.2)$ & $12(52.2)$ & $11(47.8)$ \\
\hline \multicolumn{10}{|l|}{ Risk group } \\
\hline Standard & $146(100)$ & $37(25.3)$ & $109(74.7)$ & $44(30.1)$ & $102(69.9)$ & $44(30.1)$ & $102(69.9)$ & $48(32.9)$ & $98(67.1)$ \\
\hline High & $156(100)$ & $30(19.2)$ & $126(80.8)$ & $35(22.4)$ & $121(77.6)$ & $48(30.8)$ & $108(69.2)$ & $58(37.2)$ & $98(62.8)$ \\
\hline \multicolumn{10}{|c|}{ WBC $\left(1 \times 10^{9} / \mathrm{L}\right)$} \\
\hline$<10$ & $147(100)$ & $34(23.1)$ & $113(76.9)$ & $38(25.9)$ & $109(74.1)$ & $40(27.2)$ & $107(72.8)$ & $43(29.3)$ & $104(70.7)$ \\
\hline $10-20$ & $48(100)$ & $10(20.8)$ & $38(79.2)$ & $14(29.2)$ & $34(70.8)$ & $18(37.5)$ & $30(62.5)$ & $20(41.7)$ & $28(58.3)$ \\
\hline $20-50$ & $34(100)$ & $3(8.8)$ & $31(91.2)$ & $5(14.7)$ & $29(85.3)$ & $11(32.4)$ & $23(67.6)$ & $12(35.3)$ & $22(64.7)$ \\
\hline 50-100 000 & $27(100)$ & $7(25.9)$ & $20(74.1)$ & $8(29.6)$ & $19(70.4)$ & $6(22.2)$ & $21(77.8)$ & $10(37.0)$ & $17(63.0)$ \\
\hline$\geq 100$ & $46(100)$ & $13(28.3)$ & $33(71.7)$ & $14(30.4)$ & $32(69.6)$ & $17(37.0)$ & $29(63.0)$ & $21(45.7)$ & $26(54.3)$ \\
\hline
\end{tabular}

TABLE 4: Events and deaths in paediatric patients with ALL who were younger than 16 years of age and who were treated at the paediatric haematology service of the specialist "La Raza" IMSS Medical Centre.

\begin{tabular}{|c|c|c|c|c|c|c|c|c|}
\hline \multirow{3}{*}{ Characteristic } & \multicolumn{4}{|c|}{ Event } & \multicolumn{4}{|c|}{ Death } \\
\hline & \multicolumn{2}{|c|}{3 years } & \multicolumn{2}{|c|}{5 years } & \multicolumn{2}{|c|}{3 years } & \multicolumn{2}{|c|}{5 years } \\
\hline & $\begin{array}{c}\text { No } \\
n(\%)\end{array}$ & $\begin{array}{c}\text { Yes } \\
n(\%)\end{array}$ & $\begin{array}{c}\text { No } \\
n(\%)\end{array}$ & $\begin{array}{c}\text { Yes } \\
n(\%)\end{array}$ & $\begin{array}{c}\text { No } \\
n(\%)\end{array}$ & $\begin{array}{c}\text { Yes } \\
n(\%)\end{array}$ & $\begin{array}{c}\text { No } \\
n(\%)\end{array}$ & $\begin{array}{c}\text { Yes } \\
n(\%)\end{array}$ \\
\hline \multicolumn{9}{|l|}{ Sex } \\
\hline Male & $99(59.3)$ & $68(40.7)$ & $89(53.3)$ & $78(46.7)$ & $119(71.3)$ & $48(28.7)$ & $113(67.7)$ & $54(32.3)$ \\
\hline Female & $78(57.8)$ & $57(42.2)$ & $72(53.3)$ & $63(46.7)$ & $91(67.4)$ & $44(32.6)$ & $83(61.5)$ & $52(38.5)$ \\
\hline \multicolumn{9}{|l|}{ Age (years) } \\
\hline$<1$ & $0(0)$ & $1(100)$ & $0(0)$ & $1(100)$ & $1(100)$ & $0(100)$ & $0(0)$ & $1(100)$ \\
\hline $1-5$ & $79(64.8)$ & $43(35.2)$ & $71(58.2)$ & $51(41.8)$ & $93(76.2)$ & $29(23.8)$ & $87(71.3)$ & $35(28.7)$ \\
\hline $5.1-9.99$ & $35(53.0)$ & $31(47.0)$ & $32(48.5)$ & $34(51.5)$ & $44(66.7)$ & $22(33.3)$ & $40(60.6)$ & $26(39.4)$ \\
\hline$\geq 10$ & $63(55.8)$ & $50(44.2)$ & $58(51.3)$ & $55(48.7)$ & $72(63.7)$ & $41(36.3)$ & $69(61.1)$ & $44(38.9)$ \\
\hline \multicolumn{9}{|c|}{ Immunophenotype } \\
\hline $\mathrm{B}$ & $166(59.5)$ & $113(40.5)$ & $150(53.8)$ & $129(46.2)$ & $198(71.0)$ & $81(29.0)$ & $185(66.3)$ & $94(33.7)$ \\
\hline $\mathrm{T}$ & $11(47.8)$ & $12(52.2)$ & $11(47.8)$ & $12(52.2)$ & $12(52.2)$ & $11(47.8)$ & $11(47.8)$ & $12(52.2)$ \\
\hline \multicolumn{9}{|c|}{ WBC count $\left(1 \times 10^{9} / \mathrm{L}\right)$} \\
\hline$<10$ & $91(61.9)$ & $56(38.1)$ & $87(59.2)$ & $60(40.8)$ & $107(72.8)$ & $40(27.2)$ & $104(70.7)$ & $43(29.3)$ \\
\hline $10-20$ & $26(54.2)$ & $22(45.8)$ & $21(43.8)$ & $27(56.3)$ & $30(62.5)$ & $18(37.5)$ & $28(58.3)$ & $20(41.7)$ \\
\hline $20-50$ & $20(58.8)$ & $14(41.2)$ & $18(52.9)$ & $16(47.1)$ & $23(67.6)$ & $11(32.4)$ & $22(64.7)$ & $12(35.3)$ \\
\hline $50-100$ & $17(63.0)$ & $10(37.0)$ & $16(59.3)$ & $11(40.7)$ & $21(77.8)$ & $6(22.2)$ & $17(63.0)$ & $10(37.0)$ \\
\hline$>100$ & $23(50.0)$ & $23(50.0)$ & $19(41.3)$ & $27(58.7)$ & $29(63.0)$ & $17(37.0)$ & $25(54.3)$ & $21(45.7)$ \\
\hline \multicolumn{9}{|l|}{ Risk group } \\
\hline Standard & $84(57.5)$ & $62(42.5)$ & $76(52.1)$ & $70(47.9)$ & $102(69.9)$ & $44(30.1)$ & $98(67.1)$ & $48(32.9)$ \\
\hline High & $93(59.6)$ & $63(40.4)$ & $85(54.3)$ & $71(45.5)$ & $108(69.2)$ & $48(30.8)$ & $98(62.8)$ & $58(37.2)$ \\
\hline
\end{tabular}


TABLE 5: Cox proportional-hazards model. Disease-free survival and death in paediatric patients with ALL who were younger than 16 years of age and who were treated at the paediatric haematology service of the specialist "La Raza" IMSS Medical Centre.

\begin{tabular}{|c|c|c|c|c|c|c|c|c|c|c|c|c|}
\hline \multirow{2}{*}{ Characteristic } & \multicolumn{3}{|c|}{ DFS 3 years } & \multicolumn{3}{|c|}{ DFS 5 years } & \multicolumn{3}{|c|}{ Death 3 years } & \multicolumn{3}{|c|}{ Death 5 years } \\
\hline & RR & $95 \%$ CI & $P$ & RR & $95 \%$ CI & $P$ & $\mathrm{RR}$ & $95 \%$ CI & $P$ & $\mathrm{RR}$ & $95 \%$ CI & $P$ \\
\hline \multicolumn{13}{|l|}{ Sex } \\
\hline \multicolumn{13}{|l|}{ Male } \\
\hline Female & 1.202 & $0.839-1.721$ & 0.316 & 1.137 & $0.811-1.595$ & 0.457 & 1.307 & $0.861-1.984$ & 0.208 & 1.413 & $0.956-2.088$ & 0.082 \\
\hline \multicolumn{13}{|l|}{ Age (years) } \\
\hline$<1$ & 4.288 & $0.531-34.611$ & 0.172 & 3.947 & $0.495-31.454$ & 0.195 & 0.000 & 0.000 & 0.000 & 3.616 & $0.446-29.352$ & 0.229 \\
\hline $1-5$ & 1 & & & 1 & & & 1 & & & 1 & & \\
\hline $5.1-9.99$ & 1.504 & $0.942-2.403$ & 0.087 & 1.384 & $0.891-2.148$ & 0.148 & 1.556 & $0.887-2.728$ & 0.123 & 4.573 & $0.940-2.633$ & 0.085 \\
\hline$>10$ & 1.464 & $0.958-2.239$ & 0.078 & 1.358 & $0.912-2.021$ & 0.132 & 1.699 & $1.036-2.787$ & 0.036 & 1.561 & $0.982-2.479$ & 0.060 \\
\hline \multicolumn{13}{|c|}{ Leucocytes $\left(1 \times 10^{9} / \mathrm{L}\right)$} \\
\hline \multicolumn{13}{|l|}{$<10$} \\
\hline $10-20$ & 1.302 & $0.792-2.140$ & 0.297 & 1.489 & $0.942-2.354$ & 0.089 & 1.437 & $0.821-2.516$ & 0.205 & 1.495 & $0.876-2.550$ & 0.140 \\
\hline $20-50$ & 1.193 & $0.655-2.175$ & 0.564 & 1.253 & $0.712-2.205$ & 0.435 & 1.286 & $0.650-2.545$ & 0.470 & 1.322 & $0.688-2.541$ & 0.402 \\
\hline $50-100$ & 1.133 & $0.520-2.470$ & 0.753 & 1.167 & $0.556-2.449$ & 0.683 & 0.990 & $0.390-2.510$ & 0.982 & 1.374 & $0.620-3.044$ & 0.434 \\
\hline$>100$ & 1.842 & $1.033-3.285$ & 0.038 & 2.025 & $1.172-3.496$ & 0.011 & 1.604 & $0.833-3.088$ & 0.158 & 1.860 & $1.011-3.422$ & 0.046 \\
\hline \multicolumn{13}{|l|}{ Phenotype } \\
\hline \multicolumn{13}{|l|}{ B } \\
\hline $\mathrm{T}$ & 1.676 & $0.893-3.145$ & 0.108 & 1.479 & $0.794-2.754$ & 0.218 & 2.071 & $1.054-4.070$ & 0.035 & 1.930 & $1.017-3.664$ & 0.044 \\
\hline \multicolumn{13}{|l|}{ Risk } \\
\hline \multicolumn{13}{|l|}{ Standard } \\
\hline High & 0.765 & $0.481-1.216$ & 0.258 & 0.753 & $0.485-1.169$ & 0.206 & 0.823 & $0.487-1.388$ & 0.464 & 0.830 & $0.503-1.371$ & 0.467 \\
\hline
\end{tabular}

DFS: disease-free survival; RR: relative risk; CI: confidence interval.

in our population were gender (male), age (5.1-9.9 years), B cell lineage, leucocyte count $\left(>100 \times 10^{9} / \mathrm{L}\right)$, and SR. By contrast, there was a protective effect in the HR group (RR $0.83,95 \%$ CI $0.5-1.4)$. This finding suggests that determining the risk group using the NCI criteria may be imprecise and that the correct classification of risk is needed for the proper application of therapy to increase the chance that the patient can remain free of events. If precise data are not available (i.e., cytogenetic or molecular biology), a third classification of intermediate risk, as noted previously [5], may be needed. This third classification is based on minimal residual disease (MRD), determined by polymerase chain reaction (PCR) at two times, which redefines all prognostic factors. Attarbaschi et al. [30] showed that only the MRD was reliable enough to discriminate the SR and HR of relapse in a group of patients with ALL of the precursor B cell phenotype $(P=0.02)$.

In our population, most of the relapses occurred early and were most frequent in bone marrow (18.2\%). Studies of MRD have shown that the leukaemic cells found during relapse originate from residual cells and are resistant to chemotherapy [31-33], as was observed in our results (i.e., a high percentage of deaths $(12.5 \%)$ were associated with leukaemic activity). Other factors that could have influenced the relapse rate in our study were the use of methotrexate $\left(4 \mathrm{~g} / \mathrm{m}^{2}\right)$ in a $1 \mathrm{~h}$ infusion followed by generous doses of leucovorin, because the levels of monitoring were not available. Mikkelsen et al. [34] reported that shortening the time of infusion of methotrexate reduced the accumulation of active methotrexate in the leukaemic cells and therefore the antileukaemic effect is reduced. Skärby et al. [35] reported that high doses of leucovorin during the treatment with high doses of methotrexate reduced the average cure rate in children with ALL.

The rate of isolated CNS relapse was low (2.6\%) and was associated with the intensive use of directed therapy to the CNS ( 3 IT in IR, 4 in the 2 weeks of the therapy directed to the CNS in a total of 12 until the 24 months of treatment were completed, joined to radiotherapy in the patients with $\mathrm{HR}$ ) and the systemic chemotherapy, as was proven in clinical assays in the groups of leukaemia: CCG [7], BFM [8], and St. Jude [9]. These studies have shown that if additional therapy is directed to the CNS early, it is possible to replace radiotherapy, which may be reserved only for those patients with a higher risk of relapse or with CNS3 status, because of its secondary effects, which have been observed in long-term survivors of ALL after either chemotherapy or radiotherapy [36-38].

The factors more strongly associated were ages $<1$ year and $>10$ years, leucocyte count $>100 \times 10^{9} / \mathrm{L}$, and $\mathrm{T}$ cell phenotype. These factors have also been identified previously as indicators of poor prognosis [23, 28, 29, 39-41]. In our study, the factor most strongly associated with the occurrence of events was a leucocyte count $>100 \times 10^{9} / \mathrm{L}$. We used this criterion to classify our patients as very high risk and then treated them with more intensive chemotherapy. Our poor results were associated with toxic death during induction, complete remission during treatment, and relapse. Toxicity remains as a main obstacle to the success of treatment of our population. 
Our results are similar to those reported from other Central American countries (Nicaragua, Costa Rica, El Salvador, Honduras, and Panama) by the AHOPCA ALL 2008 study [26], in which the treatment was based on local regimens adapted from the BFM group to the local situation. We now have two projects underway to reduce the frequency of toxicity in children with ALL, especially in malnourished children.

Several groups have observed that the results of the treatment of children with ALL depend on the biological diversity of the leukaemic cells, the multidrug treatment scheme, and individual variability in the metabolism of the drugs. However, in developing countries, socioeconomic status is also a strong predictor that is independent of the relapse and mortality associated with the treatment $[42,43]$. In Mexico, this can be an important factor because most of our patients live far from the treatment centres, which causes delays in the timely management of their disease. Bhatia et al. [44] showed that the lack of adherence to mercaptopurine increased the risk of relapse in Hispanic patients compared with nonHispanics. Recently, polymorphisms such as ARID5B have been associated with a higher incidence of ALL and greater risk of relapse in Hispanic patients, a finding that may explain the higher incidence and worse results in Hispanic patients $[45,46]$. Additionally, there arrangement of CRLF2 associated with mutations in JAK and alterations in IKZF1 in Hispanics may be responsible for the poor response of ALL of B cell lineage [47].

To improve our results, we decided that, during the induction phase, methotrexate should be given at a dose of $1 \mathrm{~g} / \mathrm{m}^{2}$ infused for $24 \mathrm{~h}$ instead of $4 \mathrm{~g} / \mathrm{m}^{2}$ infused for $1 \mathrm{~h}$, and we then changed the dose of leucovorin to $25 \mathrm{mg} / \mathrm{m}^{2} \mathrm{SC}$ to 48 and $52 \mathrm{~h}$. And the next dosage should be given according to the level of methotrexate. To improve the stratification of risk, we suggest redefining the risk groups by introducing an intermediate risk group, another HR group, and a very $\mathrm{HR}$ group. We also recommend promoting the implementation of reference centres for the cytogenetic and molecular diagnosis of MRD and the formation of national cooperative groups linked to international groups.

We consider that protocol DFCI 00-01 is an excellent of chemotherapy scheme. With the exception of induction, all of the treatments can be applied to outpatients, which will decrease the cost. However, the disadvantage for lowor middle-income countries such as Mexico is the lack of alternatives for asparaginase, which could contribute to the relapse observed in some patients when asparaginase is suspended.

\section{Conflict of Interests}

The authors declare that there is no conflict of interests regarding the publication of this paper.

\section{Acknowledgments}

This work was funded by the National Council of Science and Technology (CONACyT), Grant 2010-1-141026 and by Mexican Institute of Social Security, Grants
FIS/IMSS/PROT/PRIO/11/017 and FIS/IMSS/PROT/G12/ 1134, (all to Juan Manuel Mejía-Aranguré). Funding to cover the costs of the translation and publishing was provided by the División de Desarrollo de la Investigación del IMSS.

\section{References}

[1] M. L. Pérez-Saldívar, A. Fajardo-Gutiérrez, R. Bernaldéz-Ríos et al., "Chilhodhood acute leukemias are frecuent in México City: descriptive epidemiology," BMC Cancer, vol. 11, pp. 355365, 2011.

[2] K. Pritchard-Jones, R. Pieters, G. H. Reaman et al., "Sustaining innovation and improvement in the treatment of childhood cancer: Lessons from high-income countries," The Lancet Oncology, vol. 14, no. 3, pp. e95-e103, 2013.

[3] S. P. Hunger, "Expanding clinical trial networks in pediatric acute lymphoblastic leukemia," Journal of Clinical Oncology, vol. 32, no. 3, pp. e169-e170, 2014.

[4] S. P. Hunger, X. Lu, M. Devidas et al., "Improved survival for children and adolescents with acute lymphoblastic leukemia between 1990 and 2005: a report from the children's oncology group," Journal of Clinical Oncology, vol. 30, no. 14, pp. 16631669, 2012.

[5] V. Conter, C. R. Bartram, M. G. Valsecchi et al., "Molecular response to treatment redefines all prognostic factors in children and adolescents with B-cell precursor acute lymphoblastic leukemia: Results in 3184 patients of the AIEOP-BFMALL 2000 study," Blood, vol. 115, no. 16, pp. 3206-3214, 2010.

[6] M. Tsuchida, A. Ohara, A. Manabe et al., "Long-term results of Tokyo children's cancer study group trials for childhood acute lymphoblastic leukemia, 1984-1999," Leukemia, vol. 24, no. 2, pp. 383-396, 2010.

[7] P. S. Gaynon, A. L. Angiolillo, W. L. Carroll et al., "Long-term results of the children's cancer group studies for childhood acute lymphoblastic leukemia 1983-2002: a children's oncology group report," Leukemia, vol. 24, no. 2, pp. 285-297, 2010.

[8] A. Möricke, M. Zimmermann, A. Reiter et al., "Long-term results of five consecutive trials in childhood acute lymphoblastic leukemia performed by the ALL-BFM study group from 1981 to 2000," Leukemia, vol. 24, no. 2, pp. 265-284, 2010.

[9] C. H. Pui, D. Pei, J. T. Sandlund et al., "Long-term results of st jude total therapy studies 11,12,13A, 13B, and 14 for childhood acute lymphoblastic leukemia," Leukemia, vol. 24, no. 2, pp. 371$382,2010$.

[10] L. B. Silverman, K. E. Stevenson, J. E. O’Brien et al., "Longterm results of dana-farber cancer institute all consortium protocols for children with newly diagnosed acute lymphoblastic leukemia (1985-2000)," Leukemia, vol. 24, no. 2, pp. 320-334, 2010.

[11] V. Conter, M. Aricò, G. Basso et al., "Long-term results of the Italian association of pediatric hematology and oncology (AIEOP) Studies 82, 87, 88, 91 and 95 for childhood acute lymphoblastic leukemia," Leukemia, vol. 24, no. 2, pp. 255-264, 2010.

[12] I. Magrath, E. Steliarova-Foucher, S. Epelman et al., "Paediatric cancer in low-income and middle-income countries," The Lancet Oncology, vol. 14, no. 3, pp. e104-e116, 2013.

[13] A. Möricke, A. Reiter, M. Zimmermann et al., "Risk- ajusted therapy of acute lymphoblastic leukemia can decrece treatment burden and improve survival: treatment results of 2169 unselected pediatric and adolescent patients in the trial ALL-BFM 95," Blood, vol. 111, pp. 4477-4489, 2008. 
[14] T. Flohr, A. Schrauder, G. Cazzaniga et al., "Minimal residual disease-directed risk stratification using real-time quantitative PCR analysis of immunoglobulin and T-cell receptor gene rearrangements in the international multicenter trial AIEOPBFM ALL 2000 for childhood acute lymphoblastic leukemia," Leukemia, vol. 22, no. 4, pp. 771-782, 2008.

[15] M. Schrappe, M. G. Valsecchi, C. R. Bartram et al., "Late $\mathrm{MRD}$ response determines relapse risk overall and in subsets of childhood T-cell ALL: results of the AIEOP-BFM-ALL 2000 study," Blood, vol. 118, no. 8, pp. 2077-2084, 2011.

[16] A. V. Moorman, H. M. Ensor, S. M. Richards et al., "Prognostic effect of chromosomal abnormalities in childhood Bcell precursor acute lymphoblastic leukaemia: results from the UK Medical Research Council ALL97/99 randomised trial," The Lancet Oncology, vol. 11, no. 5, pp. 429-438, 2010.

[17] M. J. Sutcliffe, J. J. Shuster, H. N. Sather et al., "High concordance from independent studies by the Children's Cancer Group (CCG) and Pediatric Oncology Group (POG) associating favorable prognosis with combined trisomies 4,10 , and 17 in children with NCI Standard-Risk B-precursor Acute Lymphoblastic Leukemia: a Children's Oncology Group (COG) initiative," Leukemia, vol. 19, no. 5, pp. 734-740, 2005.

[18] M. Smith, D. Arthur, B. Camitta et al., "Uniform approach to risk classification and treatment assignment for children with acute lymphoblastic leukemia," Journal of Clinical Oncology, vol. 14, no. 1, pp. 18-24, 1996.

[19] M. Lauten, G. Cario, G. Asgedom, K. Welte, and M. Schrappe, "Protein expression of the glucocorticoid receptor in childhood acute lymphoblastic leukemia," Haematologica, vol. 88, no. 11, pp. 1253-1258, 2003.

[20] M. Dördelmann, A. Reiter, A. Borkhardt et al., "Prednisone response is the strongest predictor of treatment outcome in infant acute lymphoblastic leukemia," Blood, vol. 94, no. 4, pp. 1209-1217, 1999.

[21] A. Manabe, A. Ohara, D. Hasegawa et al., "Significance of the complete clearance of peripheral blasts after 7 days of prednisolone treatment in children with acute lymphoblastic leukemia: the Tokyo Children's Cancer Study Group Study L9915," Haematologica, vol. 93, no. 8, pp. 1155-1160, 2008.

[22] J. M. LeClerc, A. L. Billett, R. D. Gelber et al., "Treatment of childhood acute lymphoblastic leukemia: results of DanaFarber ALL Consortium Protocol 87-01," Journal of Clinical Oncology, vol. 20, no. 1, pp. 237-246, 2002.

[23] A. Moghrabi, D. E. Levy, B. Asselin et al., "Results of the dana-farber cancer institute all consortium protocol 95-01 for children with acute lymphoblastic leukemia," Blood, vol. 109, no. 3, pp. 896-904, 2007.

[24] L. M. Vrooman, K. E. Stevenson, J. G. Supko et al., "Postinduction dexamethasone and individualized dosing of Escherichia coli l-asparaginase each improve outcome of children and adolescents with newly diagnosed acute lymphoblastic leukemia: Results from a randomized study-Dana-Farber Cancer Institute ALL Consortium Protocol 00-01," Journal of Clinical Oncology, vol. 31, no. 9, pp. 1202-1210, 2013.

[25] N. A. López-Facundo, J. Talavera-Piña, and I. Tejocote-Romero, "Mortalidad temprana en niños con leucemia linfoblástica aguda en un país en vías de desarrollo; factores asociados con el pronóstico," GAMO, vol. 7, no. 3, pp. 93-101, 2008.

[26] M. Navarrete, E. Rossi, E. Brivio et al., "Treatment of childhood acute lymphoblastic leukemia in central America: a lowermiddle income countries experience," Pediatric Blood and Cancer, vol. 61, no. 5, pp. 803-809, 2014.
[27] C. Pacheco, G. Lucchini, M. G. Valsecchi et al., "Childhood acute lymphoblastic leukemia in Nicaragua: long-term results in the context of an International Cooperative Program," Pediatric Blood and Cancer, vol. 61, no. 5, pp. 827-832, 2014.

[28] S. G. Kong, J. H. Seo, S. E. Jun, B. K. Lee, and Y. T. Lim, “Childhood acute lymphoblastic leukemia with hyperleukocytosis at presentation," Blood Research, vol. 49, no. 1, pp. 29-35, 2014.

[29] E. J. Lowe, C.-H. Pui, M. L. Hancock, T. L. Geiger, R. B. Khan, and J. T. Sandlund, "Early complications in children with acute lymphoblastic leukemia presenting with hyperleukocytosis," Pediatric Blood \& Cancer, vol. 45, no. 1, pp. 10-15, 2005.

[30] A. Attarbaschi, G. Mann, R. Panzer-Grümayer et al., "Minimal residual disease values discriminate between low and high relapse risk in children with B-cell precursor acute lymphoblastic leukemia and an intrachromosomal amplification of chromosome 21: the Austrian and German acute lymphoblastic leukemia Berlin-Frankfurt-Münster (ALL-BFM) trials," Journal of Clinical Oncology, vol. 26, no. 18, pp. 3046-3050, 2008.

[31] L. C. Bailey, B. J. Lange, S. R. Rheingold, and N. J. Bunin, "Bonemarrow relapse in paediatric acute lymphoblastic leukaemia," The Lancet Oncology, vol. 9, no. 9, pp. 873-883, 2008.

[32] P. Bader, H. Kreyenberg, G. H. R. Henze et al., "Prognostic value of minimal residual disease quantification before allogeneic stem-cell transplantation in relapsed childhood acute lymphoblastic leukemia: the ALL-REZ BFM Study Group," Journal of Clinical Oncology, vol. 27, no. 3, pp. 377-384, 2009.

[33] H. G. Einsiedel, A. von Stackelberg, R. Hartmann et al., "Longterm outcome in children with relapsed ALL by risk-stratified salvage therapy: results of trial Acute Lymphoblastic LeukemiaRelapse Study of the Berlin-Frankfurt-Münster Group 87," Journal of Clinical Oncology, vol. 23, no. 31, pp. 7942-7950, 2005.

[34] T. S. Mikkelsen, A. Sparreboom, C. Cheng et al., "Shortening infusion time for high-dose methotrexate alters antileukemic effects: a randomized prospective: clinical trial," Journal of Clinical Oncology, vol. 29, no. 13, pp. 1771-1778, 2011.

[35] T. V. C. Skärby, H. Anderson, J. Heldrup, J. A. Kanerva, H. Seidel, and K. Schmiegelow, "High leucovorin doses during high-dose methotrexate treatment may reduce the cure rate in childhood acute lymphoblastic leukemia," Leukemia, vol. 20, no. 11, pp. 1955-1962, 2006.

[36] T. Langer, P. Martus, H. Ottensmeier, H. Hertzberg, J. D. Beck, and W. Meier, "CNS late-effects after ALL therapy in childhood. Part III: neuropsychological performance in long-term survivors of childhood ALL: impairments of concentration, attention, and memory," Medical and Pediatric Oncology, vol. 38, no. 5, pp. 320-328, 2002.

[37] R. E. Goldsby, Q. Liu, P. C. Nathan et al., "Late-occurring neurologic sequelae in adult survivors of childhood acute lymphoblastic leukemia: a report from the childhood cancer survivor study," Journal of Clinical Oncology, vol. 28, no. 2, pp. 324-331, 2010.

[38] A. Singla, J. E. B. O’Neill, E. Smith, and R. M. Scott, “Cavernous malformations of the brain after treatment for acute lymphocytic leukemia: Presentation and long-term follow-up: clinical article," Journal of Neurosurgery: Pediatrics, vol. 11, no. 2, pp. 127132, 2013.

[39] W. Stock, M. La, B. Sanford et al., "What determines the outcomes for adolescents and young adults with acute lymphoblastic leukemia treated on cooperative group protocols? A comparison of children'scancer group and cancer an leukemia Group B studies," Blood, vol. 112, no. 5, pp. 1646-1654, 2008. 
[40] A. Möricke, M. Zimmermann, A. Reiter et al., "Prognostic impact of age in children and adolescents with acute lymphoblastic leukemia: data from the trials ALL-BFM 86, 90, and 95," Klinische Padiatrie, vol. 217, no. 6, pp. 310-320, 2005.

[41] J. M. Goldberg, L. B. Silverman, D. E. Levy et al., "Childhood T-cell acute lymphoblastic leukemia: the Dana-Farber Cancer Institute Acute Lymphoblastic Leukemia Consortium experience," Journal of Clinical Oncology, vol. 21, no. 19, pp. 3616-3622, 2003.

[42] S. Gupta, F. A. Antillon, M. Bonilla et al., "Treatment-related mortality in children with acute lymphoblastic leukemia in Central America," Cancer, vol. 117, no. 20, pp. 4788-4795, 2011.

[43] M. B. Viana, R. A. F. Fernandes, R. I. De Carvalho, and M. Murao, "Low socioeconomic status is a strong independent predictor of relapse in childhood acute lymphoblastic leukemia," International Journal of Cancer, vol. 78, no. 11, pp. 56-61, 1998.

[44] S. Bhatia, W. Landier, M. Shangguan et al., "Nonadherence to oral mercaptopurine and risk of relapse in hispanic and nonhispanic white children with acute lymphoblastic leukemia: a report from the Children's Oncology Group," Journal of Clinical Oncology, vol. 30, no. 17, pp. 2094-2101, 2012.

[45] H. Xu, C. Cheng, M. Devidas et al., "ARID5B genetic polymorphisms contribute to racial disparities in the incidence and treatment outcome of childhood acute lymphoblastic leukemia," Journal of Clinical Oncology, vol. 30, no. 7, pp. 751757, 2012.

[46] A. P. Chokkalingam, L. I. Hsu, C. Metayer et al., "Genetic variants in ARID5B and CEBPE are childhood ALL susceptibility loci in Hispanics," Cancer Causes and Control, vol. 24, no. 10, pp. 1789-1795, 2013.

[47] R. C. Harvey, C. G. Mullighan, I.-M. Chen et al., "Rearrangement of CRLF2 is associated with mutation of JAK kinases, alteration of IKZF1, Hispanic/Latino ethnicity, and a poor outcome in pediatric B-progenitor acute lymphoblastic leukemia," Blood, vol. 115, no. 26, pp. 5312-5321, 2010. 


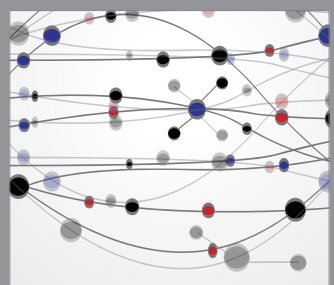

The Scientific World Journal
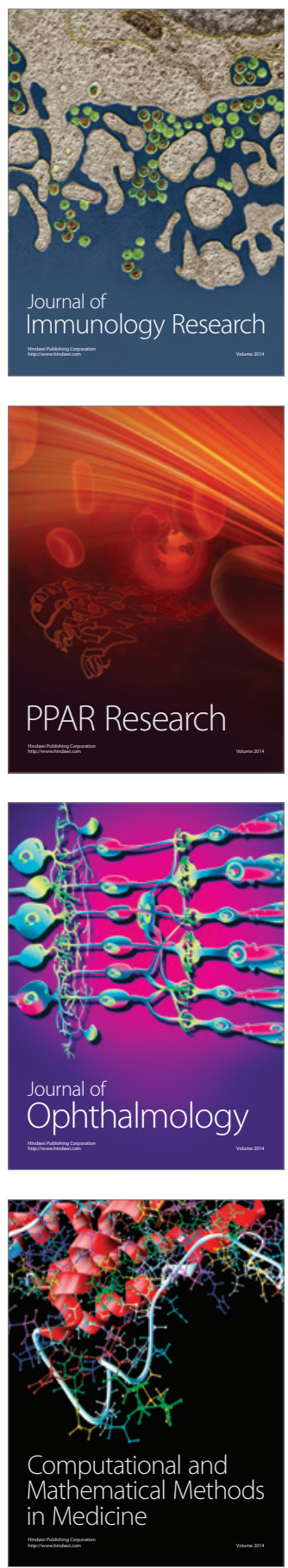

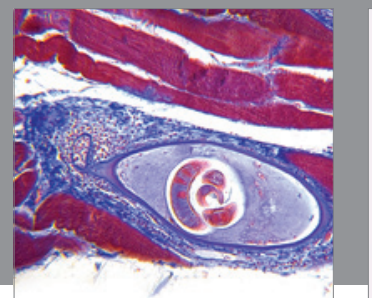

Gastroenterology

Research and Practice
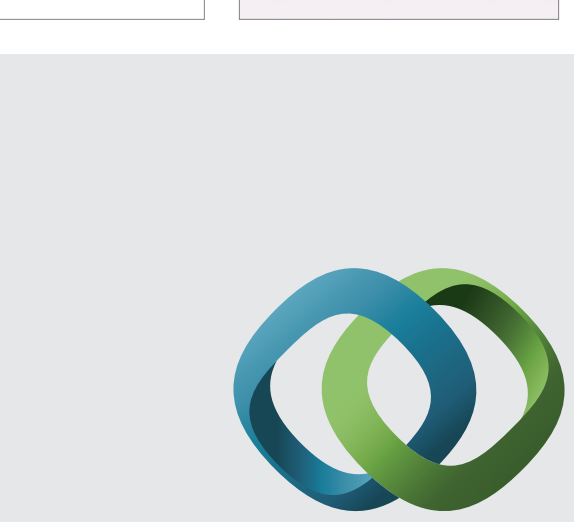

\section{Hindawi}

Submit your manuscripts at

http://www.hindawi.com
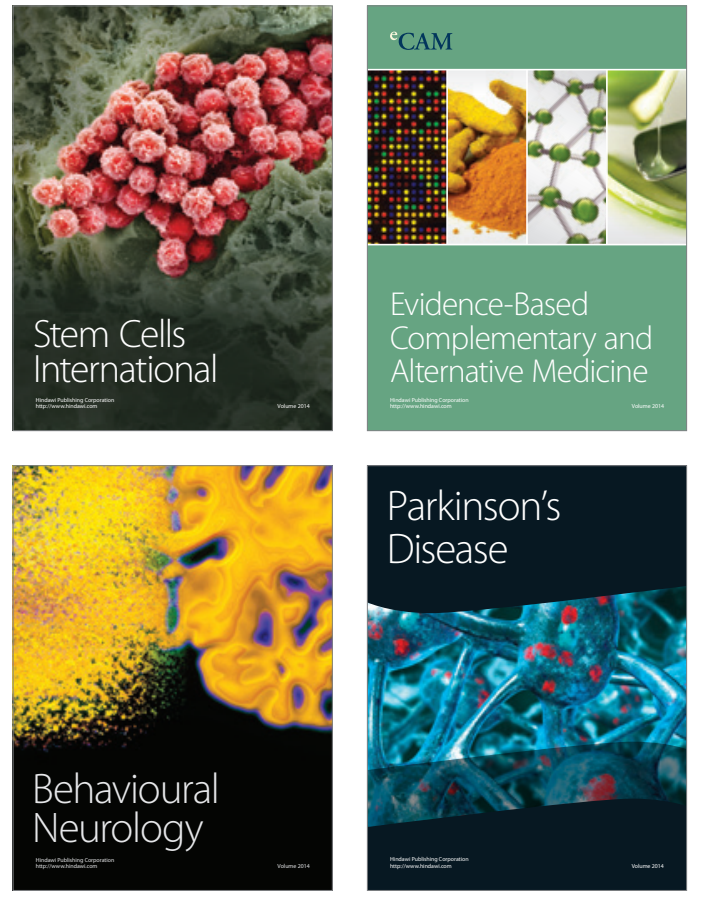
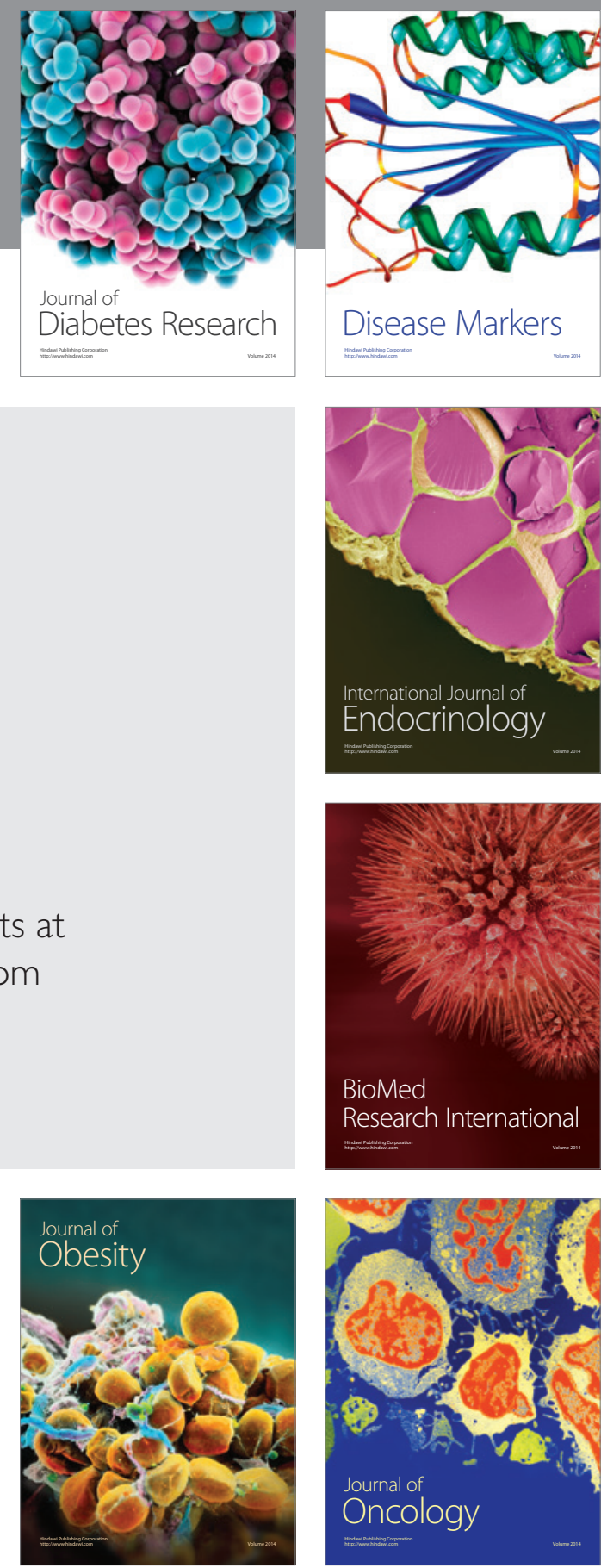

Disease Markers
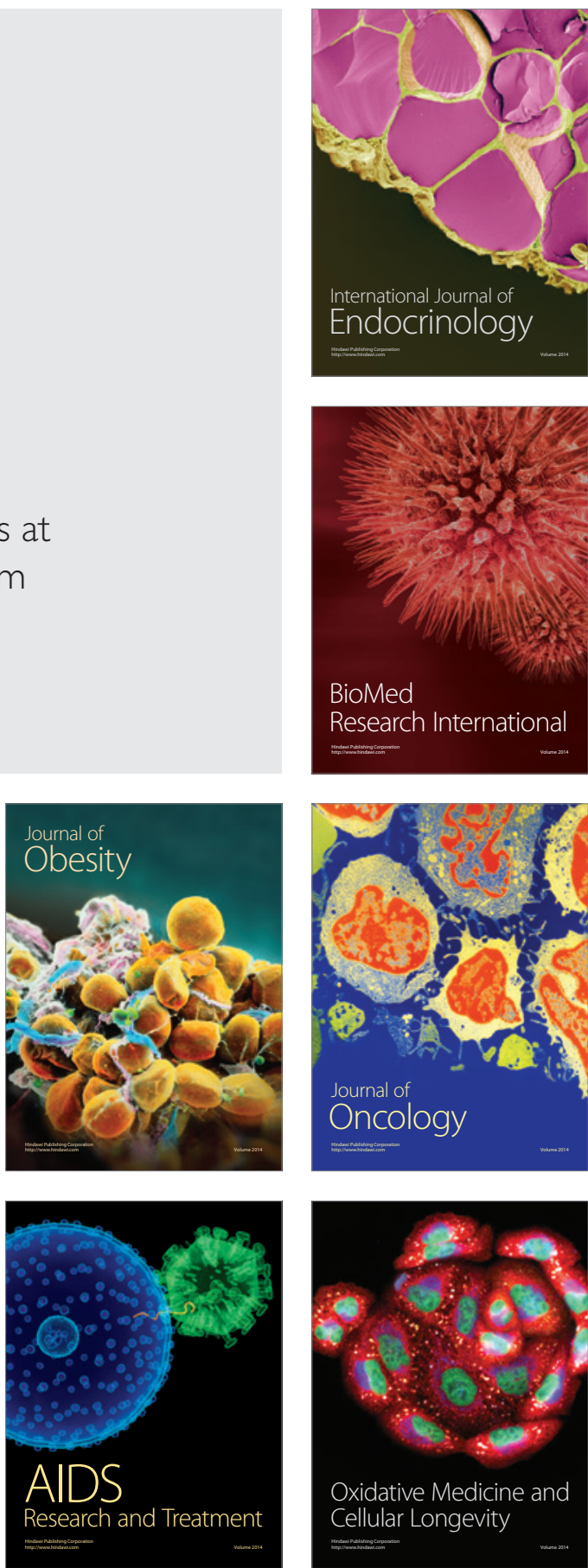